Juan Ramón Moreno - Francisco José Martínez: La narrativa del colonizador: la América Precolombina, un contenido 'invisible' en los libros de texto españoles, Izquierdas, 49, febrero 2020:341-351

\title{
La narrativa del colonizador: la América Precolombina, un contenido 'invisible' en los libros de texto españoles
}

Colonizer's narrative. Precolumbian America, an 'invisible'content in the spanish textbooks

\author{
Juan Ramón Moreno Vera* \\ Francisco José Martínez Llorca**
}

Resumen: Este trabajo pretende analizar la presencia de las culturas precolombinas en los libros de texto escolares, que en Ciencias Sociales se erige como uno de los instrumentos más eficaces para el tratamiento didáctico de la diversidad cultural. Se han analizado libros de Primaria y Secundaria españoles, evidenciando el poco peso que formalmente se le da a este contenido, la invisibilidad de las culturas prehispánicas y la visión eurocéntrica de este acontecimiento histórico.

Palabras clave: Culturas precolombinas, América, descubrimiento, Colón, Ciencias Sociales

Abstract: This research pretends to analyze the treatment that precolumbian cultures have in the Social Sciences textbooks, as they are one of the most effective tool in a didactic approach to cultural diversity. We have analyzed different Primary and Secondary Spanish textbooks, and it could be observed the lack of importance of these contents, the invisibility of the precolumbian cultures and the eurocentric view of this moment of the history.

Keywords: Precolumbian cultures, America, Discovery, Columbus, Social Sciences.

Recibido: 13 octubre 2018 Aceptado: 20 diciembre 2018

\section{Introducción}

Que, en 1492, Cristóbal Colón llegó a América es uno de los datos que pocos olvidan de su etapa escolar, una de las fechas que quedan grabadas en nosotros y que pocas veces requiere parar para pensarla. No obstante, el hecho de conocer la fecha y su principal protagonista de manera contundente no implica el no cuestionarse si es suficiente para afirmar que los más pequeños están enriqueciéndose de historia, y si esa historia es justa y equitativa con la realidad e importancia de los hechos acontecidos y transmitidos.

\footnotetext{
* Nacionalidad: española. Coautor de la publicación. Profesor Contratado Doctor de Didáctica de la Historia en la Facultad de Educación de la Universidad de Murcia (España). Departamento de Didáctica de las Ciencias Matemáticas y Sociales. Facultad de Educación. Universidad de Murcia C/ Campus de Espinardo, 11. 30100 Murcia (España). Correo electrónico: ir.moreno@um.es

** Nacionalidad: española. Coautor de la publicación. Alumno predoctoral de Didáctica de la Historia en la Facultad de Educación de la Universidad de Murcia (España). Departamento de Didáctica de las Ciencias Matemáticas y Sociales. Facultad de Educación. Universidad de Murcia C/ Campus de Espinardo, 11. 30100 Murcia (España). Correo electrónico: franjmll@gmail.com
} 
De hecho, como comentaban Seixas y Morton ${ }^{1}$ el hecho de aprender las nociones del tiempo cronológico no implica en absoluto que el alumnado haya aprendido a pensar históricamente. Es decir, para Pagés y Santisteban ${ }^{2}$ una de las herramientas fundamentales en la enseñanza de la historia es el aprendizaje del tiempo cronológico (la división temporal, las etapas de la historia, los hitos que marcan los cambios o la sucesión de los principales acontecimientos históricos), sin embargo, durante años el alumnado tenía como única misión este aprendizaje cronológico (muchas veces memorístico de la historia) y dejaba a un lado la repercusión social de la historia, lo que suponía para los ciudadanos los distintos hechos históricos. Por eso, Seixas y Morton ${ }^{3}$ hablan de seis cualidades históricas fundamentales que el alumnado debe dominar para pensar históricamente.

Así pues, en lugar de aprender de memoria la fecha, el nombre de Colón o el acontecimiento que le hizo famoso, sería todavía más importante que el alumnado indagase sobre las causas y consecuencias que la colonización americana tuvo, los cambios que produjo en la nueva sociedad globalizada que engendró o la sumisión que supuso esta conquista para los pueblos originarios del continente americano. Los alumnos tienen la visión aventurera de alguien que zarpó con sus barcos, dispuesto a encontrar el Nuevo Mundo del que todos hablaban y que cuando dio con él, este se incorporó en los mapas, como un trozo de tierra que emerge de la nada y a partir de ahora hay que empezar a incluirlo, sin olvidar nunca que fue un descubrimiento, nuestro descubrimiento. España aprendió de las Indias, aunque la imagen sea que los conseguimos hacer evolucionar y les aportamos todo el saber y desarrollo europeo, centro de nuestro mundo ${ }^{4}$. La idea del "descubrimiento" como hito histórico ha calado durante años en el imaginario educativo del país colonizador, sin que exista una reflexión histórica a partir de las fuentes que nos hagan ver que fue un acontecimiento poliédrico mucho más complejo y que tuvo grandes repercusiones para las sociedades que lo sufrieron (también para las que se beneficiaron).

La enseñanza de la historia debe huir del simple objetivo de trasmitir las historias "oficiales", y buscar que al alumno se exponga a esas narrativas ya hechas y las cuestione, explore fuentes contradictorias, y pueda explicar y comprender un acontecimiento, sus antecedentes y sus consecuencias sobre el devenir de una sociedad ${ }^{5}$. Como afirman Seixas y Morton ${ }^{6}$, la historia debe abordar contenidos relevantes tanto en el hecho en sí como en su significación para el lugar y momento donde se imparte enseñanza. El pasado se presenta, pues, como el reconocimiento de una realidad en permanente conexión con el presente inmediato, y en el caso de Iberoamérica y España ese nexo es el elemento cultural.

El enfoque del descubrimiento de América en un material presente en el contexto educativo curricular como es el libro de texto, que en Ciencias Sociales es uno de los instrumentos más eficaces para el tratamiento didáctico de la diversidad cultural 7 , no trasciende más allá del de transmisor de contenidos discursivos sociales y culturales cerrados, sin dar pie a la libre formación del pensamiento histórico por parte del alumno.

Así pues, esta investigación tiene como objetivo el análisis de tres libros de texto españoles en el curso de $2^{\circ}$ de Educación Secundaria Obligatoria (ESO) para establecer una comparación entre ellos y delimitar cuál es el tratamiento que hacen los manuales de texto en España del tema de las causas de la

\footnotetext{
1 Peter Seixas \& Tom Morton, The Big Six Historical Thinking Concepts, Toronto, Ed. Nelson, 2013

2 Joan Pagés \& Antoni Santisteban, Didáctica del conocimiento del medio social y cultural en la Educación Primaria, Madrid, Editorial Síntesis, 2011

3 Seixas \& Morton, Op. Cit.

${ }^{4}$ Rafael Valls, "La enseñanza española de la historia y su dimensión Iberoamericana”, Revista Didáctica de las Ciencias Experimentales y Sociales, 26, Valencia, 2012, 121-143

5 Alberto Rosa, "Memoria, historia e identidad. Una reflexión sobre el papel de la enseñanza de la historia en el desarrollo de la ciudadanía", Mario Carretero y James Voss (eds.), Aprender y pensar la bistoria, Buenos Aires, Amorrortu, 2004

${ }^{6}$ Seixas \& Morton, Op. Cit.

${ }^{7}$ Joaquín Prats, "Criterios para la elección del libro de texto de historia". Íber: Didáctica de las ciencias sociales, geografia e historia, 70, Barcelona, 2011, 7-13.
} 
conquista de América y qué imagen reflejan de las culturas precolombinas que habitaban el continente americano antes de la llegada de los españoles.

\section{Marco Teórico}

\subsection{Avances de la América Precolombina y aportaciones a la cultura europea}

Para mucha gente es desconocida la enorme riqueza artística que se acumuló en América durante los veinte siglos que precedieron a la conquista española. Impulsados por un fanatismo que los cegaba a la belleza, los conquistadores se dedicaron a destruir todo lo que encontraron, pero lo que sobrevivió a los siglos atestigua un majestuoso linaje de culturas arcaicas, que se manifestaron grandiosamente en todas las artes. En el ámbito de la medicina, Hernán Cortés, en su Segunda Carta de Relación, ya informaba a Carlos V del impresionante desarrollo Azteca:

No me mandes médicos ni cirujanos porque los de aquí son mejores que los de Castilla [...] Hay calles de herbolarios donde se venden de todas las raíces y yerbas medicinales que en la tierra se hayan. Hay casas de boticarios donde se venden las medicinas hechas, así potables como ungüentos y emplastos 8

América aportaría la quina, la coca, el guayacán, la jalapa, el ruibarbo, la zarzaparrilla, el toloache, el ricino, la valeriana, el tamarindo, el árnica, el yaloxochitl, el hule y el tabaco, que se empleaba por sus virtudes curativas. Los cirujanos indígenas ya operaban el cerebro, como está plenamente demostrado por los descubrimientos arqueológicos del Perú y México, y los dentistas precolombinos realizaban incrustaciones dentarias, ornamentales y curativas. En alimentación nos dejaron el tomate, el chocolate, la vainilla, el maíz, el cacahuate, la patata, el frijol, el aguacate, el chile, la calabaza, el pepino, la papaya y el pavo.

En cuestiones de navegación a finales del siglo XV el Inca Tupad Yupanqui organizó una expedición y llegó hacia la isla de Pascua y de igual manera a la Polinesia mostrando conocimientos de marinería y de astronomía. La ingeniería constructiva e hidráulica indígena y la creación de ciudades perfectamente urbanizadas, edificios monumentales y profusa creación artística integrada a su arquitectura no pasaron desapercibidas para los descubridores.

Ya conocían y trabajaban el algodón, así como la orfebrería en oro y la fundición de este, al igual que de plata, cobre y bronce. Tallaban la piedra y el jade, trabajaban la alfarería y la cerámica, que en Nazca llego a utilizar hasta once colores, y se han encontrado ejemplares de flautas de pan o tambores. En cuestiones del lenguaje se llegó a descubrir que los Mayas conocían al igual que los chinos la escritura "morfosilábica". Existen todavía alrededor de 250 lenguas menores en América. El español hablado actualmente en el continente está fuertemente influido por palabras de las lenguas aborígenes que habitaron las distintas regiones, aportando términos y costumbres que reflejan la profunda cultura que si bien, fue sometida por el conquistador, mantuvo muchas de sus características esenciales.

La constitución de Europa como nueva entidad histórica en la Edad Moderna se hizo posible, con el trabajo gratuito de indios, negros y mestizos de América, con su avanzada tecnología en la minería y en la agricultura, y con sus respectivos productos, el oro, la plata, la patata, el tomate, el tabaco, etc. ${ }^{9}$. Fue sobre esa base que se configuró la región americana como sede del control de las rutas atlánticas, decisivas

\footnotetext{
8 Jorge Cervantes, “Algunas aportaciones de América latina a la cultura universal”, Revista Archipiélago, 50 (13), Ciudad de México, 2003, 33-34

9 Aníbal Quijano, “Colonialidad del poder, eurocentrismo y América Latina”, Edgardo Lander (comp.) La colonialidad del saber: eurocentrismo y ciencias sociales. Perspectivas Latinoamericanas, Buenos Aires, CLACSO, 2000
} 
en el mercado mundial. Ambos continentes se produjeron históricamente de forma mutua, como nuevas identidades geoculturales del mundo moderno.

\subsection{Tratamiento de las culturas precolombinas en el currículum escolar español}

La presencia de los países iberoamericanos en los libros de texto escolares ha experimentado distintos grados de intensidad según las épocas y los países ${ }^{10}$, dedicando extensiones variables en sus páginas a los contenidos relacionados con sus acontecimientos históricos. En los programas educativos más recientes, publicados en 2015 por el Ministerio de Educación, la mención al tema iberoamericano aparece en los currículos de la ESO bajo la denominación de "Conquista y colonización de América". En los apartados que el currículo hace mención a las primeras civilizaciones, se observa que se continúa haciendo mención exclusiva a Mesopotamia y Egipto, así como a continuación los grandes imperios clásicos griego y romano. Ninguna mención a la civilización transoceánica. En los estándares de evaluación el currículo recoge lo siguiente.

33.1. Conoce los principales hechos de la expansión de Aragón y de Castilla por el mundo. 34.1. Explica las distintas causas que condujeron al descubrimiento de América para los europeos, a su conquista y a su colonización.

34.2. Sopesa interpretaciones conflictivas sobre la conquista y colonización de América.

Como se puede comprobar en los estándares de evaluación el foco principal se establece sobre el proceso de conquista y colonización, en ningún momento se plantea interés por las culturas o civilizaciones, y el único acercamiento sutil a estas es el hecho de definir como "situación conflictiva" el proceso colonizador.

Cuestión diferente es la profundidad con que estas temáticas son abordadas en los manuales. Esto depende directamente de los contenidos históricos asignados a cada curso. En el caso de la secundaria obligatoria, y más concretamente en segundo curso de la ESO, los contenidos a tratar comprenden las etapas de la Edad Media y Moderna, y es complicado dedicar el tiempo requerido al tratamiento de los temas de una manera exhaustiva y profunda

El descubrimiento de América se enmarca dentro de los viajes europeos ${ }^{11}$, en busca de nuevas rutas comerciales y, desde la perspectiva europeísta reinante en los libros, fue el inicio de la hegemonía europea en el mundo. La primera constatación de esto se encuentra en los titulares de los capítulos dedicados a esta cuestión. Sin apenas excepciones, los manuales se refieren a "la expansión de Europa en la Edad Moderna", "los europeos en tierras lejanas" o "Europa encuentra nuevos mundos", lo que ya manifiesta un enfoque europeo del tema tal como corroboran fragmentos de texto que pueden extraerse, por ejemplo, de uno de los libros de Vicens Vives:

Se produjo a partir de entonces una apertura espectacular del comercio y de la civilización europeos, que se impusieron en todos los continentes y en todos los mares. La supremacía de Europa durará hasta principios del siglo XX.12

${ }^{10}$ Carmen Arteaga y Pedro Alemán, "Representación del Caribe en libros de texto de Primaria venezolanos", Revista de pedagogía, 28 (83), Caracas, 2007

11 Rafael Valls Montés, "Europa y la dimensión europea en los manuales españoles de Historia de la educación secundaria”, Aula-Historia Social, (14), Madrid, 2004, 78-86.

12 Margarita García Sebastián, Cristina Gatell Arimont, Marc Llorens Serrano, Fernando Molinero Blanco, Rosa Ortega Canadell; José Pons Granja, Joan Roig Obiol y Carles Viver Pi-Sunyer, Tiempo 2. Ciencias Sociales: Geografía e Historia. Educación Secundaria, Alaquás, Ed. Vicen Vives, 1997 
En lo que a las culturas precolombinas se refiere, se suele diferenciar entre las tres grandes civilizaciones que llegaron a crear un imperio, como fueron los mayas, aztecas e incas, de las que se destaca los logros comentados anteriormente en matemáticas, astronomía, arquitectura, agricultura y escritura; y por otro lado aquellas otras culturas menos desarrolladas las cuales casi no se analizan.

En España, como media, las sociedades precolombinas ocupan un espacio entre dos y cuatro páginas de los libros de texto, un aumento con respecto a lo que figuraban hace décadas, aunque siga siendo de forma escueta. En comparación también ha evolucionado el trato dado a estas civilizaciones, que ha pasado del "aborigen salvaje" a una consideración más desarrollada de su civilización ${ }^{13}$.

Bellati y Gámez ${ }^{14}$ afirmaron que la mención a las civilizaciones prehispánicas se realiza siempre situándolas en tiempos históricos atemporales y se explican en función de lo que se encontraron los europeos en su llegada al continente americano, "invisibilizando" a las sociedades y culturas americanas en este proceso histórico. Tal y como enuncian estos autores:

Si a lo largo de los contenidos de Ciencias Sociales no se potencia la visibilidad de continentes como América (...), dejando totalmente al margen el conocimiento global de la pluralidad de culturas a nivel mundial, no se puede exigir al alumnado un conocimiento crítico de la población actual. (...). Toda esta falta de trayectoria y perspectiva histórica del pasado americano puede provocar que el alumnado no se enfrente de un modo intercultural al tema del "Descubrimiento de América"15

El objetivo socializador de la enseñanza de la Historia y de las Ciencias Sociales, presente en los currículos es el de desarrollar los conceptos de identidad y alteridad, dentro de la competencia social y ciudadana, y de su planteamiento inclusivo en Educación Primaria. Por esto, se adopta el fin de aproximar el alumnado de Primaria a las raíces históricas de las sociedades actuales y a valorar las diferentes manifestaciones culturales que conviven en un tiempo y espacio determinados.

\subsection{Las culturas prehispánicas en los libros de texto latinoamericanos}

El problema de la invisibilización de los pueblos originarios de América latina no se circunscribe al ámbito nacional escolar español, de hecho, existen investigaciones que demuestran que en el contexto iberoamericano también se dio un proceso similar. Así pues, Linares, Alderoqui y Ricardes ${ }^{16}$ nos ilustran sobre el caso de los libros de texto argentinos que hacia mitad del siglo XIX fueron decisivos en la creación de un "imaginario nacional para la Argentina blanca". Las minorías étnicas y las poblaciones indígenas en Argentina fueron deliberadamente invisibilizadas por el sistema, que se equiparaba así al resto de culturas occidentales, escondiendo su pasado e identidad original de la enseñanza formal.

De hecho, el caso de Argentina no es el único en América latina, lo que evidencia la falta de debate en la investigación educativa acerca del tema de la descolonización, el racismo y la invisibilidad de los pueblos originarios del continente americano. Corona y Le Mur ${ }^{17}$ nos comentan el caso de México y de los libros de texto escolares gratuitos que publica la Secretaría de Educación Pública, en su análisis de los años 2012 a 2015. Para las autoras los libros de texto mexicanos siguen demostrando la pervivencia de estereotipos racistas con respecto a la población indígena mexicana. De hecho, de 522 imágenes mostradas sobre estos

\footnotetext{
13 Valls, Op. Cit.

14 Ilaria Bellatti y Virginia Gámez, "La historia de Iberoamérica en los currículos escolares: un enfoque intercultural", Íber: Didáctica de las Ciencias Sociales, Geografía e Historia, 75, Barcelona, 2013, pp. 43-50

15 Bellati y Gámez, op. cit. 43-50

16 María Cristina Linares, Silvia Alderoqui \& Mariano Ricardes, "Ausentes presentes. Representaciones de indígenas y afrodescendientes en imágenes y textos escolares. Una muestra itinerante del Museo de las Escuelas", Revista Iberoamericana de Patrimonio Histórico-Educativo, 3 (2), Campinas, 2017, pp. 357-368

17 Sarah Corona Berkin \& Rozenn Le Mûr, "Racismo en la imagen de los indígenas en los libos de texto gratuitos (2012-2015)", Comunicación y sociedad, 28, México, 2017, pp. 11-33
} 
pueblos en los distintos libros de texto de esos años, la gran mayoría, el $40 \%$ muestran la población indígena como representante del pasado prehispánico como si no existiese hoy en día, mientras que el resto de imágenes enseñan a la población indígena como folklórico $(34 \%)$, en situación de pobreza (2\%), campesino $(6.5 \%)$ o como origen del mestizo (1.5\%). Tan solo el $14 \%$ de las imágenes consideran al indígena como un ciudadano más.

Un análisis similar en el caso de México lo señalan Pacheco Ladrón de Guevara, Navarro y Cayeros $^{18}$, quedando la población indígena en los libros de texto gratuitos mexicanos en una situación de dominación o rechazo frente a las jerarquías sociales imperantes y, por tanto, encontrando poco margen por parte de la población mestiza actual a encontrar referentes históricos o sociales por parte de los pueblos originales.

Un proceso similar a los de Argentina y México se evidencia también en Perú, donde Zárate ${ }^{19}$ analiza las representaciones sobre los indígenas en algunos manuales de texto peruanos. En concreto compara dos manuales, el del Ministerio de Educación y el de la Editorial Santillana. En sus conclusiones comenta que apenas hay diferencias entre ambos textos y que la población original de América latina viene excluida de determinadas acciones sociales y que, cuando es incluida, lo hace con algunas connotaciones negativas o racistas deslegitimando así su presencia como un actor social histórico en el desarrollo del país.

En absoluto nos deben extrañar estas consideraciones sobre la imagen y la invisibilidad de los pueblos originarios americanos en los libros de texto, ya que como nos indica Nahuelpán ${ }^{20}$, la construcción de la imagen del "indio" se configuró desde un punto de vista desigual, quedando el indígena como un "ser inferior" cultural y civilizadamente con respecto a los sujetos colonizadores que educaron "como seres superiores o civilizados" a los pueblos indígenas. La deconstrucción de estas lógicas narrativas históricas requiere de un proceso de crítica y autocrítica de los sistemas de jerarquía sociales impuestos hasta la fecha. El autor comenta el caso de la colonización del pueblo mapuche en Chile, también invisibilizado y deslegitimado durante años.

De todos modos, en los últimos años existen investigaciones que demuestran que otra nueva corriente de pensamiento crítico está acercándose a esta problemática histórica en nuestros libros de texto y, poco a poco, la mirada sobre los pueblos originarios de América latina va reflejando las preocupaciones en torno a su invisibilidad, exclusión y estereotipación. Lewkowicz y Rodríguez ${ }^{21}$, por ejemplo, señalan que en las dos últimas décadas los problemas de diversidad con respecto a los pueblos originarios americanos han tenido una amplia presencia en la agenda de las políticas públicas y derechos. Así pues, desde el contexto argentino indican como ha ido cambiando la imagen hegemónica de una Argentina culturalmente blanca y occidental en el contexto escolar, apareciendo nuevas preocupaciones sobre la población americana prehispánica desde finales del siglo XIX hasta nuestros días. De ese modo señalan el avance de esta población desde ser considerados "indios salvajes" a "pueblos originarios".

Una conclusión similar a la que llegan Benavides y Guido22, que hacen hincapié en el abordaje de la diferencia cultural por parte de los manuales de texto en Colombia. Las autoras comentan que, por lo que respecta, al análisis del contenido conceptual de los libros escolares se destaca una nueva dinámica que se sumerge en las miradas críticas que los pueblos étnicos han sufrido, poniendo, cada vez más, el

18 Lourdes Pacheco Ladrón de Guevara, Maía del Refugio Navarro \& Laura I. Cayeros, "Los pueblos indios en los libros de texto gratuitos", Revista Mexicana de Investigación Educativa, 16 (49), México, 2011, pp. 525-544

19 Adolfo Zárate Pérez, "Las representaciones sobe indígenas en los libros de texto de Ciencias Sociales en el Perú", Discurso y sociedad, 5 (2), Perú, 2011, pp. 333-375

${ }^{20}$ Héctor J. Nahuelpán M., "El lugar del "indio” en la investigación social. Reflexiones en torno a un debate político y epistémico aún pendiente”, Revista austral de Ciencias Sociales, 24, Chile, 2013, pp. 71-91

21 Mariana Lewkovicz \& Martha Rodríguez, "Las sociedades aborígenes en los textos escolares: de "indios salvajes" a "pueblos originarios”. Una mirada en la larga duración”, Clio \& Asociados, 20, Buenos Aires, 2015, pp. 116-137

22 Angie L. Benavides \& Sandra P. Guido, "Libros de texto en ciencias sociales: el abordaje de la diferencia cultural", Revista Kavilando, 18 (2), Colombia, 2016, pp. 157-168 
foco sobre el sujeto y su reconocimiento. Así, se puede observar un tránsito, lento, desde un modelo asimilacionista hacia otro multiculturalista desde el punto de vista educativo.

\section{Metodología}

En el momento que se realiza este estudio existen dos cursos escolares claros en los que tiene lugar la enseñanza del "Descubrimiento de América": uno es $5^{\circ}$ de Primaria y el otro $2^{\circ}$ de E.S.O. La comparativa se establece entre distintos manuales del segundo curso de Educación Secundaria Obligatoria (ESO) que es donde en mayor cantidad se pueden observar los contenidos relativos al tema de las culturas precolombinas y la conquista de América. Los objetivos específicos de este estudio serían:

- Analizar las causas que motivan el viaje de Cristóbal Colón y la llegada de los españoles al continente americano

- Establecer criterios de comparación sobre el contenido conceptual que cada libro de texto aporta sobre este tema, sobre las causas de la llegada a América, los personajes que la protagonizan y el tratamiento que tienen las civilizaciones que allí vivían previamente.

El instrumento de recogida de datos que se representa en la Tabla 1, muestra las distintas variables de investigación analizadas. Las categorías y sus correspondientes ítems observados y analizados han sido los siguientes:

Tabla 1. Ítems analizados en la comparación de libros de texto. Fuente: Elaboración propia CUESTIONES DE FORMA CUESTIONES DE CONTENIDO

$\begin{array}{ll}\text { Extensión del tema de estudio en el libro de } & \text { Causas del descubrimiento } \\ \text { texto } & \text { Mención a anteriores exploraciones } \\ \text { Extensión con respecto a otras civilizaciones o } & \text { Cristóbal Colón } \\ \text { culturas } & \text { Culturas precolombinas } \\ \text { Tratamiento de los protagonistas de la historia } & \text { Proceso de colonización } \\ \text { Tratamiento de la llegada a América } & \text { Importancia del descubrimiento }\end{array}$

Fuente: Elaboración propia

Para establecer el marco empírico de esta investigación se ha utilizado una metodología mixta cualitativa y cuantitativa, en la que se analizan los enunciados y afirmaciones sobre las culturas precolombinas que se recogen en los libros de texto españoles, aunque al mismo tiempo se han cuantificado las variables e ítems que se repiten en todos los ellos para poder establecer un marco comparativo claro de los resultados de la investigación de los diferentes manuales escolares.

La selección de la muestra ha sido dirigida, puesto que los libros de texto que se han analizado pertenecen, como ya se ha comentado previamente al curso de $2^{\circ}$ de la ESO, al ser el lugar donde se ve en la asignatura de Ciencias Sociales (en su área de Historia) el contenido relativo al continente americano. Es importante señalar que se han escogido tanto, editoriales nacionales (SM y Anaya) como una editorial que diseña los libros en la Comunitat Valenciana (Oxford), por su carácter bilingüe, motivo por el cual en el análisis de los textos su narrativa usa el idioma catalán. 


\section{Resultados}

En el caso de los libros de $2^{\circ}$ de ESO actuales, las tres editoriales incluyen el Descubrimiento de América como un apartado de una de las unidades didácticas y no destacan a los protagonistas de esta conquista de manera individualizada si no que los mantienen como partícipes de la historia y de la narración en el texto, sin aportar más datos sobre ellos de los que afectan al hecho del descubrimiento en sí. No dan una gran importancia a las culturas precolombinas, situándolas en la mayoría de los casos en desigualdad con otras culturas de las consideradas influyentes en la cultura española actual, como es la islámica.

En la dualidad Descubrimiento-Conquista, cada palabra toma un protagonismo según el libro que se consulte. A "descubrimiento" siempre se recurre cuando se quiere aludir a los logros tecnológicos alcanzados para hacer realidad la llegada a América, mientras que la "conquista" siempre va relacionada a la supremacía española presente en el mismo acontecimiento. En esta cuestión se puede observar como los libros que hacen mayor hincapié en "conquista", resaltan en el contenido el dominio sobre los tres imperios amerindios por parte de los españoles, el sometimiento por causas de fuerza y superioridad, y la escasa o nula mención a su desarrollo en ese momento.

Tabla 2. Resultados en los libros de $2^{\circ}$ de la ESO.

\begin{tabular}{|c|c|c|c|c|}
\hline \multicolumn{2}{|c|}{ Categoría / ítem } & Oxford Ed. & SM & Anaya \\
\hline \multirow{3}{*}{ 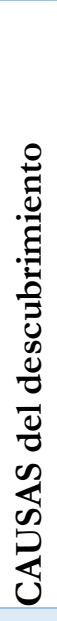 } & $\begin{array}{l}\text { Encuentro casual } \\
\text { por búsqueda de } \\
\text { nuevas rutas }\end{array}$ & $\begin{array}{l}{[\ldots] \text { amb el }} \\
\text { propòsitd'arribar a les } \\
\text { Índies orientals, però on va } \\
\text { arribar }[\ldots]\end{array}$ & $\begin{array}{l}{[\ldots] \text { Colón estaba }} \\
\text { convenido de poder } \\
\text { alcanzar las costas } \\
\text { de Asia }[\ldots]\end{array}$ & $\begin{array}{l}{[\ldots] \text { el propósito }} \\
\text { principal de los } \\
\text { descubrimientos era } \\
\text { encontrar nuevas } \\
\text { rutas }[. . .]\end{array}$ \\
\hline & $\begin{array}{l}\text { La de Colón fue } \\
\text { una más de las } \\
\text { muchas } \\
\text { expediciones }\end{array}$ & $\begin{array}{l}{[. . .] \text { els portuguesos van }} \\
\text { vorejar la costa africana } \\
{[\ldots] \text { Els relats de Marco }} \\
\text { Polo }[\ldots]\end{array}$ & $\begin{array}{l}\text { Enrique el } \\
\text { Navegante, } \\
\text { Bartolomé Díaz, } \\
\text { Vasco de } \\
\text { Gama... }\end{array}$ & $\begin{array}{l}\text { Indica a los } \\
\text { portugueses como } \\
\text { iniciadores }\end{array}$ \\
\hline & $\begin{array}{l}\text { Un navegante más, } \\
\text { que pensó una ruta } \\
\text { alternativa }\end{array}$ & $\begin{array}{l}{[. . .] \text { Colón, després de }} \\
\text { negociacions ambs els Reis } \\
\text { Catòlics }[. . .]\end{array}$ & $\begin{array}{l}{[\ldots] \text { Cristóbal }} \\
\text { Colón era un } \\
\text { navegante genovés } \\
\text { convencido de }[\ldots]\end{array}$ & $\begin{array}{l}{[\ldots] \text { este navegante }} \\
\text { ideó llegar a la India } \\
\text { por el oeste }[. . .]\end{array}$ \\
\hline \multirow{3}{*}{ 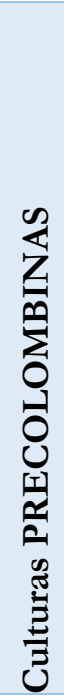 } & $\begin{array}{l}\text { Citadas como un } \\
\text { descubrimiento } \\
\text { más de los } \\
\text { navegantes }\end{array}$ & $\begin{array}{l}{[\ldots] \text { posteriorment es }} \\
\text { van dominar els imperis } \\
\text { asteca, maia i inca }[. .]\end{array}$ & & \\
\hline & $\begin{array}{l}\text { Citadas por su } \\
\text { importancia y } \\
\text { avances previos a } \\
\text { la llegada }\end{array}$ & & $\begin{array}{l}{[\ldots] \text { tres culturas }} \\
\text { muy evolucionadas: } \\
\text { las culturas Maya y } \\
\text { Azteca }[\ldots]\end{array}$ & \\
\hline & $\begin{array}{l}\text { Citadas como } \\
\text { beneficio posterior } \\
\text { y su influjo en } \\
\text { Europa }\end{array}$ & & & $\begin{array}{l}\text { En el momento } \\
\text { de los } \\
\text { descubrimientos } \\
\text { no se las cita, } \\
\text { aparecen ya en el } \\
\text { tema de la } \\
\text { Hegemonía } \\
\text { española, como }\end{array}$ \\
\hline
\end{tabular}




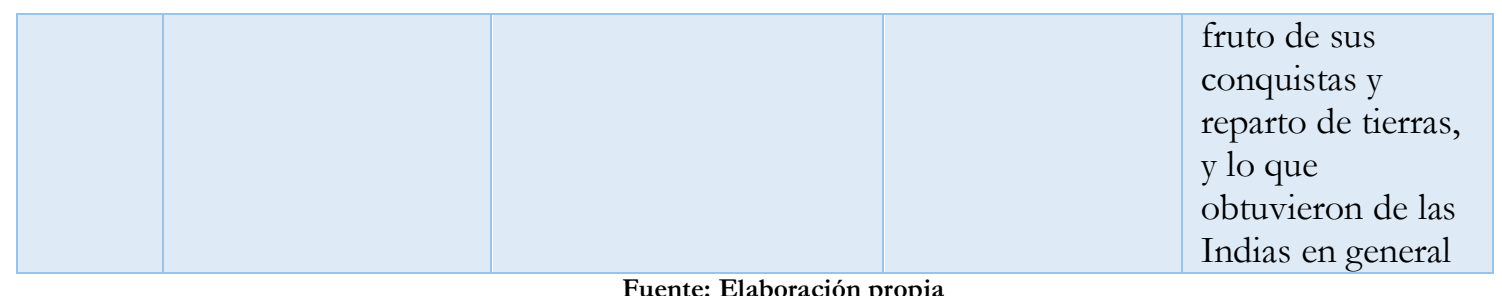

Sin embargo, sí que coinciden los libros de secundaria en resaltar tres aspectos: el hecho de que Colón fue quien tuvo la idea y la propuso a los Reyes Católicos como empresa comercial; el que fue una expedición más como otras tantas, sin ningún fin místico de encontrar el Nuevo Mundo, y que la llegada a América se produjo de manera casual, interponiéndose entre los navegantes y su objetivo real.

La presentación de las culturas precolombinas resulta sin embargo muy diferente en cada uno de los libros: Oxford las menciona a la llegada de los navegantes anticipando su posterior conquista, SM destaca su desarrollo y civilización en el momento del descubrimiento, y Anaya, por su parte, las trata como el premio de la conquista, refiriéndose a ellas desde el reparto de tierras y lo que los europeos obtuvieron de beneficio. Sí que coinciden en la importancia del descubrimiento para Europa, a nivel de apertura de miras, aunque resaltando la hegemonía de la península ibérica (Castilla y Portugal) por lo que suponía de cara a su riqueza y ampliación de fronteras.

En lo que respecta a los libros de texto se observa como el tema del descubrimiento de América se trata de un modo un poco menos profundo, dedicándoles en algunos casos sólo un subapartado dentro de un apartado de la unidad. Igualmente, sucinta es la mención a las culturas precolombinas, equiparable a otras culturas que tampoco son trabajadas en profundidad.

Cristóbal Colón sí que recibe en alguno de ellos un trato protagonista, convirtiéndose en el eje de la narración del Descubrimiento; y siempre pesa más este término frente al de "conquista".

Todos los libros coinciden en destacar la importancia del descubrimiento para España a nivel de poder con respecto a los demás países. Ninguno de ellos hace mención a otras navegaciones previas a las de Colón, y únicamente en uno se menciona a las tres principales civilizaciones precolombinas como parte del descubrimiento.

\section{Conclusiones}

Con respecto al tratamiento del hecho histórico hay realidades constatadas e inamovibles que se transmiten fielmente en cualquiera de los cursos y se mantienen con el paso de los años, como las relacionadas con Colón o los motivos de su viaje. Lo cual nos habla bien a las claras de la narrativa oficial del colonizador que se perpetúa a través de la perspectiva eurocéntrica ${ }^{23}$. No obstante, varía el tratamiento de otros como las culturas precolombinas, en las que todos los manuales de texto coinciden en destacar tres de ellas sobre el resto, pero no hay una forma común de tratarlas.

En comparación con el islam, cuyas aportaciones a la cultura española son indudables, las civilizaciones precolombinas en muchos de los libros no son más que tratadas como indígenas que no tuvieron más remedio que someterse al poder del imperio español, pese a que alguno de estos libros a continuación relata las aportaciones importadas desde las Indias a nuestro territorio ${ }^{24}$. A pesar de esto, pocos son los que las consideran importantes y reseñables, como si no existieran hasta que los españoles decidieron conquistarlas.

La dualidad Descubrimiento-Conquista peca en ocasiones de ambigüedad, y sería buena idea comenzar por aclarar primero ambos términos. ¿El descubrimiento es solo el momento del avistamiento?

\footnotetext{
${ }^{23}$ Quijano, Op. Cit.

${ }^{24}$ Cervantes, Op. Cit.
} 
¿La conquista comienza solo en el momento que los españoles empiezan a expoliar y someter? ¿Se debería plantear, en los tiempos que corren, el enfocar la conquista desde un punto de vista más crítico ${ }^{25}$ ? En el caso de las persecuciones cristianas en los primeros siglos, o del nazismo más reciente, son igualmente abusos de poder y sometimiento a pueblos y colectivos, sin embargo, en la conquista de América no se aprecia esa connotación negativa con la que se tratan esos temas mencionados, se enfoca desde un punto de vista heroico, de muestra de poder, e incluso "necesario" para el progreso, pero nunca se menciona el tratamiento violento del colonizador sobre el pueblo sometido ${ }^{26}$.

A colación de este tema, en ninguno de los libros aparece el término "mestizaje", clave en la confluencia de las culturas españolas y amerindias. Quizás sería una buena idea hacer que los alumnos aprendan desde pequeños a llamar a las cosas por su nombre, y no sólo hablar de historias de batallas y héroes. Algo que, como ya hemos visto, sí empieza a aflorar en los libros de texto latinoamericanos, aunque solo en un los últimos años ${ }^{27}$.

Dejamos para finalizar dos cuestiones que consideramos serían interesantes llevar a cabo en futuros estudios. Por un lado, el profundizar en el entendimiento de los alumnos en torno al concepto de "Descubrimiento de América" y "Conquista de América"28; y por otro lado estudiar la progresión del tratamiento de este hecho histórico a lo largo del tiempo en nuestro país o en otros países para ver cómo ha ido evolucionando según nuestra propia relación con el continente y el momento vivido en nuestro país. Sería un estudio interesante que podría reivindicar el papel de las culturas amerindias junto al resto de las culturas de influencia en la historia universal a nivel escolar.

\section{Referencias bibliográficas}

Carmen Arteaga y Pedro Alemán, "Representación del Caribe en libros de texto de Primaria venezolanos", Revista de pedagogía, 28 (83), Caracas, 2007

Ilaria Bellatti y Virginia Gámez, "La historia de Iberoamérica en los currículos escolares: Un enfoque intercultural", Íber: Didáctica de las Ciencias Sociales, Geografía e Historia, 75, Barcelona, 2013, 43-50

Angie L. Benavides \& Sandra P. Guido, "Libros de texto en ciencias sociales: el abordaje de la diferencia cultural”, Revista Kavilando, 18 (2), Colombia, 2016, pp. 157-168

Ángela Bermúdez y Diego Argumero, "The narrative framing of violence in teaching resources about the Spanish conquest of America”, Panta Rei, Revista digital de ciencia y Didáctica de la Historia, 1, Murcia, 2018, 93-119

Jorge Cervantes, "Algunas aportaciones de América latina a la cultura universal”, Revista Archipiélago, 50 (13), Ciudad de México, 2003, 33-34

Sarah Corona Berkin \& Rozenn Le Mûr, "Racismo en la imagen de los indígenas en los libos de texto gratuitos (2012-2015)”, Comunicación y sociedad, 28, México, 2017, pp. 11-33

\footnotetext{
25 Rosa, Op. Cit.

26 Ángela Bermúdez y Diego Argumero, "The narrative framing of violence in teaching resources about the Spanish conquest of America”, Panta Rei, Revista digital de ciencia y Didáctica de la Historia, 1, Murcia, 2018, 93-119

27 Benavides \& Guido, Op. Cit.

28 Pedro Pérez y María Jesús García-Arévalo, "La imagen de América Latina entre la población estudiantil española (13-18 años)". Revista Iberoamericana de Educación, 6, Madrid, 1994
} 
Margarita García Sebastián, Cristina Gatell Arimont, Marc Llorens Serrano, Fernando Molinero Blanco, Rosa Ortega Canadell; José Pons Granja, Joan Roig Obiol y Carles Viver Pi-Sunyer, Tiempo 2. Ciencias Sociales: Geografía e Historia. Educación Secundaria, Alaquás, Ed. Vicen Vives, 1997

Mariana Lewkovicz \& Martha Rodríguez, "Las sociedades aborígenes en los textos escolares: de "indios salvajes" a "pueblos originarios". Una mirada en la larga duración", Clío \& Asociados, 20, Buenos Aires, 2015, pp. 116-137

María Cristina Linares, Silvia Alderoqui \& Mariano Ricardes, “Ausentes presentes. Representaciones de indígenas y afrodescendientes en imágenes y textos escolares. Una muestra itinerante del Museo de las Escuelas", Revista Iberoamericana de Patrimonio Histórico-Educativo, 3 (2), Campinas, 2017, pp. 357-368

Héctor J. Nahuelpán M., "El lugar del "indio" en la investigación social. Reflexiones en torno a un debate político y epistémico aún pendiente", Revista austral de Ciencias Sociales, 24, Chile, 2013, pp. 71-91

Lourdes Pacheco Ladrón de Guevara, Maía del Refugio Navarro \& Laura I. Cayeros, "Los pueblos indios en los libros de texto gratuitos", Revista Mexicana de Investigación Educativa, 16 (49), México, 2011, pp. 525544

Joan Pagés \& Antoni Santisteban, Didáctica del conocimiento del medio social y cultural en la Educación Primaria, Madrid, Editorial Síntesis, 2011

Pedro Pérez y María Jesús García-Arévalo, "La imagen de América Latina entre la población estudiantil española (13-18 años)”, Revista Iberoamericana de Educación, 6, Madrid, 1994

Joaquín Prats, "Criterios para la elección del libro de texto de historia", Íber: Didáctica de las ciencias sociales, geografía e historia, 70, Barcelona, 2011, 7-13.

Aníbal Quijano, "Colonialidad del poder, eurocentrismo y América Latina", Edgardo Lander (comp.) La colonialidad del saber: eurocentrismo y ciencias sociales. Perspectivas Latinoamericanas, Buenos Aires, CLACSO, 2000

Alberto Rosa, "Memoria, historia e identidad. Una reflexión sobre el papel de la enseñanza de la historia en el desarrollo de la ciudadanía", Mario Carretero y James Voss (eds.), Aprender y pensar la bistoria, Buenos Aires, Amorrortu, 2004

Peter Seixas y Tom Morton, The Big Six Historical Thinking Concepts, Toronto, Ed. Nelson, 2013

Rafael Valls Montés, "Europa y la dimensión europea en los manuales españoles de Historia de la educación secundaria", Aula-Historia Social, (14), Madrid, 2004, 78-86

Rafael Valls, "La enseñanza española de la historia y su dimensión Iberoamericana", Revista Didáctica de las Ciencias Experimentales y Sociales, 26, Valencia, 2012, 121-143

Adolfo Zárate Pérez, "Las representaciones sobe indígenas en los libros de texto de Ciencias Sociales en el Perú”, Discurso y sociedad, 5 (2), Perú, 2011, pp. 333-375 